\title{
Bacteraemia by Chryseobacterium indologenes in a patient with Lung Cancer: A Clinical and Microbiological Investigation
}

\author{
Gitali Bhagawati ${ }^{1}$, Ashutosh Bhardwaj ${ }^{2}$, Rekha Sajikumar ${ }^{3}$, Sukhwinder Pal Singh ${ }^{4}$, Sanjeev Prajapati ${ }^{5}$
}

\begin{abstract}
We present a case of bacteraemia by an unsual, instrinsically multidrug resistant organism, Chryseobacterium indologenes in a 59 year old gentleman with squamous cell carcinoma of lung with multiple metastasis. Despite of treating as per sensitivity report after isolating Chryseobacterium indologenes, patient could not be survived. The pathogenicity and predictability of the organism towards antibiotics, both in -vivo and in-vitro needs further research.

Keywords: Chryseobacterium indologenes, multi drug resistant (MDR), lung cancer

Indian Journal of Critical Care Medicine (2019): 10.5005/jp-journals-10071-23142
\end{abstract}

\section{INTRODUCTION}

Crid ryseobacterium indologenes (previously classified as Flavobacterium indologenes), a Gram negative rod is an environmental organism. Infection by this organism is usually rare; however reported cases are there causing serious infections in immunosuppressed patients from various parts of the globe ${ }^{1,2}$. The troublesome fact with this organism is that it presents a high rate of natural resistance against broad-spectrum cefem compounds including carbapenems ${ }^{2}$.

\section{Case Report}

This document reports a 59 year old gentlemen diagnosed with moderately differentiated Squamous Cell Carcinoma (SCC) of left lung with multiple metastasis in liver, brain, bone, subcutaneous tissue in chest and back, left adrenal gland, lymph nodes including right pulmonary hilar, mediastinal, bilateral axillary and right cardiophrenic angle. Tumour marker Cytokeratin (CK)7 was found to be positive. He was admitted in ward with complains of loss of appetite and generalized weakness for 3-4 days. Patient was planned for palliative External beam radiotherapy (EBRT) to address painful bony metastasis followed by systemic chemotherapy. Blood was transfused (1 unit Packed Red Blood Cells) on the day of admission in view of low Haemoglobin $(7 \mathrm{gm} / \mathrm{dl})$. Patient also had complaints of urinary retention, but due to resistance during Foley's catheterisation attempts failed and therefore cystostomy had to be done. On 3rd day of admission, patient was shifted to Medical Intensive Care Unit (ICU) due to low Glasgow Coma Scale (GCS). Central venous line (CVP) insertion was done on the same day. Investigations revealed high TLC, thrombocytopenia, dyselectrolytemia including hypernatremia, hypokalaemia, deranged Kidney Function Test (KFT). After admission to ICU, blood and urine samples were sent for culture. Both blood and urine cultures showed growth of multi-drug resistant (MDR) E.coli. Patient was receiving Injection Cefepime-tazobactum for 10 days; Injection Polymyxin B for 6 days.

After one week of stay in the ICU, repeat paired aerobic blood (Right Femoral line and central venous line) samples were taken in

\footnotetext{
$\overline{1-5}$ Department of Microbiology, Dharmshila Narayana Superspeciality
} Hospital, Delhi, India

Corresponding Author: Gitali Bhagawati, Department of Microbiology, Dharmshila Narayana Superspeciality Hospital, Delhi, India, Phone: +91-9899877146, e-mail: gitalibhagawati32@gmail.com

How to cite this article: Bhagawati G, Bhardwaj A et al. Bacteraemia by Chryseobacterium Indologenes in a patient with Lung Cancer: A Clinical and Microbiological Investigation. Indian J of Crit Care Med 2019;23(3):157-159.

Source of support: Nil

Conflict of interest: None

Becton Dickinson (BD) blood culture bottles and sent for culture. Repeat urine sample showed no growth. Paired set of aerobic blood culture samples were processed with the Bactec 1090 (Becton Dickinson, USA). Bacterial growth was detected within 48 $\mathrm{hr}$ in both the bottles of the samples. Gram stain of positive blood culture bottle showed Gram negative bacilli. Sub-cultures were done on routine Sheep Blood agar and MacConkey agar. After 24 hours of incubation, smooth, circular, yellow-pigmented colonies were grown on sheep blood agar ${ }^{3}$. On addition of 1 drop of $10 \%$ $\mathrm{KOH}$ solution, the color of the colonies was changed from yellow to red which indicates presence of flexirubin pigment. The isolate was catalase and oxidase positive, indole weakly positive and urease negative. Oxidation fermentation test results revealed: oxidation positive/ fermentation negative, mannitol positive, non- motile organism. Final identification and sensitivity of the organism was done by Vitek 2 Compact system (BioMerieux). Chryseobacterium indolegenes was isolated from both the blood culture bottles. Antimicrobial susceptibility pattern of both the isolates from blood culture showed same sensitivity pattern with MIC levels (Table 1 and Figure 1).

Patient's antibiotics were modified as per culture report and sensitivity patterns. Levofloxacin and Minocycline were added and Polymyxin B discontinued. Levofloxacin was continued for 11 days while Minocycline for 9 days.

() The Author(s). 2019 Open Access This article is distributed under the terms of the Creative Commons Attribution 4.0 International License (http://creativecommons. org/licenses/by/4.0/), which permits unrestricted use, distribution, and non-commercial reproduction in any medium, provided you give appropriate credit to the original author(s) and the source, provide a link to the Creative Commons license, and indicate if changes were made. The Creative Commons Public Domain Dedication waiver (http://creativecommons.org/publicdomain/zero/1.0/) applies to the data made available in this article, unless otherwise stated. 
Table 1: Antimicrobial susceptibility pattern of Chryseobacterium indolegenes isolated from blood culture

\begin{tabular}{lll}
\hline Antibiotic & MIC & Interpretation \\
\hline CEFTAZIDIME & $>=64$ & $\mathrm{R}$ \\
AMIKACIN & $>=64$ & $\mathrm{R}$ \\
MINOCYCLINE & $<=1$ & $\mathrm{~S}$ \\
CIPROFLOXACIN & $>=16$ & $\mathrm{R}$ \\
GENTAMYCIN & $>=16$ & $\mathrm{R}$ \\
COLISTIN & $>=16$ & $\mathrm{R}$ \\
CEFEPIME & $>=64$ & $\mathrm{R}$ \\
LEVOFLOXACIN & 4 & $\mathrm{I}$ \\
MEROPENEM & $>=16$ & $\mathrm{R}$ \\
AZTREONAM & $>=64$ & $\mathrm{R}$ \\
TICARCILLIN CLAVULANIC ACID & $>=128$ & $\mathrm{R}$ \\
IMIPENEM & $>=16$ & $\mathrm{R}$ \\
CEFOPERAZONE-SALBACTUM & $>=64$ & $\mathrm{R}$ \\
TRIMETHOPRIM- & 160 & $\mathrm{R}$ \\
SULFOMETHOXAZOLE & & \\
PIPERACILLIN-TAZOBACTUM & $>=128$ & $\mathrm{R}$ \\
TIGECYCLINE & $>=8$ & $\mathrm{R}$ \\
\hline
\end{tabular}

On 20th day of admission in ICU, there was further deterioration of patients' general condition including sensorium and Glassgow coma scale (GCS). In view of advance nature of the disease, sepsis refractory to antibiotics, dyselectrolytemia and aspiration, the patient was put on non-invasive ventilation with informed consent from the primary responsible attendant of the patient. However, the patient had an episode of bradycardia which was followed by cardiopulmonary arrest.

\section{Discussion}

Chryseobacterium spp. is not usually found in human flora but widely distributed in soil, plants, food-staffs and water ${ }^{4,5}$. In health care institutes, water systems can act as a potential reservoir for the bacteria; thus patients' may get colonized by this bug via various contaminated medical devices like endotracheal tube, tracheostomy tube etc. ${ }^{1,4,5}$ Although the pathogenicity of $C$. indologenes has not been clearly defined, biofilm production and their highly active protease have been found to be responsible for its virulence ${ }^{4,6}$.

In 1993, the first case of infection by C. indologenes was reported from a patient with ventilator associated pneumonia $(\text { VAP })^{7}$. During the period 1997 to 2001, SENTRY Antimicrobial Surveillance Program represented $0.03 \%$ of Chryseobacteria among all isolates which were responsible for bloodstream infections ${ }^{2,8,9}$. Chryseobacterium spp. usually cause infections in patients' with underlying medical illness, newborn or elderly with immunocompromising status, indwelling intravascular catheter, renal calculi long-term broad-spectrum antibiotics etc. ${ }^{1,2,4,5,8,10-12}$ Very few case reports of infection by this organism in immunocompetent patients are also available ${ }^{13,14}$. It can cause various infections like bacteriemia, ventilator associated pneumonia (VAP), pyonephritis, biliary tract infection, lumboperitoneal shunt infection, ocular infections, burn wound infections etc., ${ }^{1,15-18}$

Some authors believe that after introduction of colistin and tigecycline, prevalence of $C$. indologenes infections have been increased ${ }^{2,5}$. The organism is intrinsically resistant to carbapenems

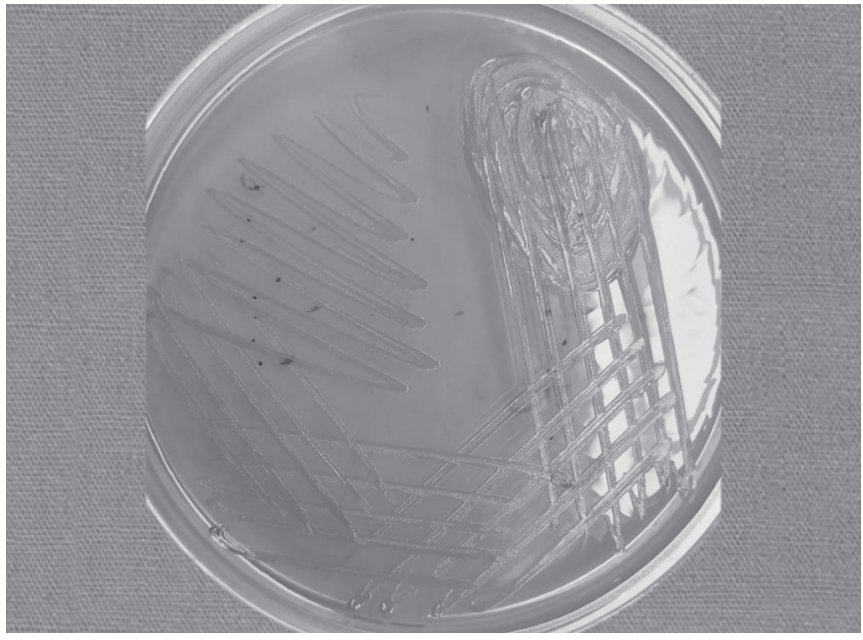

Fig. 1: Yellowish pigmented colony of Chryseobacterium indologenes in MacConkey Agar media after 48 hours of incubation

and cephalosporins due to production of molecular Class A Beta lactamases and Class B carbapenem hydrolyzing B-lactamase. However, most active agents against this bug were found to be trimethoprim-sulfamethoxazole (TMP-SMZ) and cefoperazonesulbactam ${ }^{2}$. According to the results of the SENTRY Program, $\geq 95 \%$ susceptibility was found with newer quinolones (garenoxacin, gatifloxacin, and levofloxacin) and TMP-SMX followed by piperacillin-tazobactam ( $90 \%$ susceptibility) ${ }^{8,9}$. Worldwide newer quinolones may represent the most appropriate antimicrobial agents against this pathogen'.

The present case report suggests that $C$. indologenes can cause nosocomial bacteremia in terminally ill cancer patients with other risk factors like previous MDR infections and use of broad spectrum antibiotics against them. Appropriate selection of antimicrobials is difficult despite the proper culture and sensitivity report due to unpredictable nature of the organism against the antibiotics. Further study on pathogenesis of this organism may help in future to get the proper empiric antibiotic.

\section{References}

1. G Calderón, E García, P Rojas, E García, M Rosso, A Losada et al. Chryseobacterium indologenes infection in a newborn: a case report. Journal of Medical Case Reports. 2011; 5: 10.

2. T A Teke, F N Oz, O Metin, G I Bayhan, Z G G Aydin, M Oguz et al. Chryseobacterium indologenes Septicemia in an Infant. Case Reports in Infectious Diseases. 2014; Article ID 270521, p 4.

3. J.G. Collee, R. S. Miles, B. Watt. Tests for identification of bacteria. Mackie \& McCartney Practical Medical Microbiology. 13th ed. New York: Churchill livingstone; 2008.

4. G Bhuyar, S Jain, H Shah, VK Mehta. Urinary tract infection by Chryseobacterium indologenes. Indian Journal of Medical Microbiology. 2012; 30: 370-72

5. F. Chen, G. Wang, S. Teng, T. Ou, F. Yu, W. Lee et. al. Clinical and epidemiological features of Chryseobacterium indologenes infections: analysis of 215 cases. Journal of Microbiology, Immunology and Infection. 2013; 46: 425-32.

6. Hsueh PR, Teng LJ, Ho SW, Hsieh WC, Luh KT. Clinical and microbiological characteristics of Flavobacterium indologenes infections associated with indwelling devices. Journal of Clinical Microbiology. 1996; 34:1908-13.

7. G. Srinivasan, S. Muthusamy, V. Raveendran, N. M. Joseph, J. M. Easow. Unforeseeable Presentation of Chryseobacterium Indologenes Infection in a Paediatric Patient. Biomedical Central Research Notes. 2016; 9: 212. 
8. G.B. Christakis, S. P. Perlorentzou, I. Chalkiopoulou, A. Athanasiou, Nikolas J. Legakis. Chryseobacterium indologenes Non-CatheterRelated Bacteremia in a Patient with a Solid Tumor. Journal of Clinical Microbiology. 2005; 43: 2021-23

9. Kirby, J. T., H. S. Sader, T. R. Walsh, R. N. Jones. Antimicrobial susceptibility and epidemiology of a worldwide collection of Chryseobacterium spp.: report from the SENTRY Antimicrobia Surveillance Program (1997-2001). Journal of Clinical Microbiology. 2004; 42: 445-48.

10. P. Hsueh, T. Hsiue, J. Wu et al. Flavobacterium indologenes bacteremia: clinical and microbiological characteristics. Clinical Infectious Diseases. 1996; 23: 550-55.

11. A. Cascio, G. Stassi, G. B. Costa et al. Chryseobacterium indologenes bacteraemia in a diabetic child. Journal of Medical Microbiology. 2005; 54: 677-80.

12. W. Alfouzan, R. Dhar, H. A. Hashemi, N. A. Sweih, M. J. Albert. Clinical and microbiological characteristics of Chryseobacterium spp. isolated from neonates in Kuwait. JMM Case Reports. 2014
13. V. Cunha, M. Ferreira, A. G. Fonseca, J. Diogo. Community-acquired Chryseobacterium indologenes in an immunocompetent patient. JMM Case Reports 2014

14. G. McKew, P. Bourbeau. Severe Sepsis Due to Chryseobacterium indologenes in an Immunocompetent Adventure Traveler. Journal of Clinical Microbiology. 2014; $52: 4100-01$

15. B. T. Green, P. E. Nolan. "Cellulitis and bacteraemia due to Chryseobacterium indologenes," Journal of Infection. 2001; 42: 219-20.

16. H. A. Tatari, B. I. Asmar, J. Y. Ang. Lumboperitonial shunt infection due to Chryseobacterium indologenes. Pediatric Infectious Disease Journal. 2007; 26: 657-59.

17. M. R. Bayraktar, E. Aktas, Y. Ersoy, A. Cicek, R. Durmaz. Postoperative Chryseobacterium indologenes bloodstream infection caused by contamination of distillate water. Infection Control and Hospital Epidemiology. 2007; 28: 368-69.

18. Lin YT, Jeng YY, Lin ML, Yu KW, Wang FD, Liu CY et. al. Clinical and microbiological characteristics of Chryseobacterium indologenes bacteremia. J Microbiol Immunol Infect. 2010; 43(6):498-05. 